\title{
Transição para a produção orgânica via Organização de Controle Social do Grupo Bem-Estar, Ladário-MS
}

\author{
Transition to organic production through Organization of Social \\ Control of the "Bem-Estar" Group, Ladário-MS
}

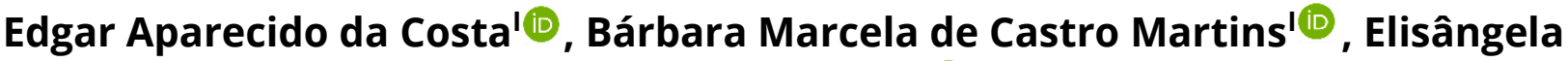 de Souza Cunha"I)}

\author{
' Universidade Federal de Mato Grosso do Sul, campus do Pantanal, Corumbá, MS, Brasil \\ "Escola Estadual Gabriel Vandoni de Barros, Corumbá, MS, Brasil
}

\section{RESUMO}

Este trabalho foi desenvolvido junto aos agricultores familiares membros do Grupo Bem-Estar de Ladário-MS, na fronteira Brasil-Bolívia, que estão em processo de transição agroecológica. O objetivo principal deste artigo é relatar as percepções dos participantes do Grupo Bem-Estar na implementação da certificação orgânica em sua propriedade e discutir as dificuldades para sua efetivação. Foram entrevistadas seis famílias e participou-se de duas reuniões para formalização da Organização de Controle Social (OCS). O grupo estudado considera a certificação importante, mas mantém a resistência quanto as anotações das informações.

Palavras-chave: Agroecologia; Agricultura Familiar; Produção orgânica

\section{ABSTRACT}

The present work was developed with family farmers, members of the "Bem-Estar de Ladário-MS" Group, on the Brazil-Bolivia border, who are in the process of agroecological transition. The main objective of this article is to report the perceptions of the "Grupo Bem-Estar" participants in the implementation of organic certification on their property, also to discuss the difficulties for its effectiveness. Six families were interviewed and participated in two meetings to formalize a Social Control Organization (SCO). The studied group understands that the certification is important but maintains the resistance regarding to the annotation of the information.

Keywords: Agroecology; Family farming; Organic production 


\section{INTRODUÇÃO}

Neste início de século XXI, observa-se uma crescente preocupação de parte significativa da população mundial em relação a oferta de alimentos, não apenas no que diz respeito a quantidade, mas, também, a qualidade dos produtos. Homens e mulheres apresentam interesse por produtos que vão além dos parâmetros de conformidade e regulamentação. Valorizam, cada vez mais, os elementos ambientais e sociais que formam o contexto da produção (NEVES, 2004).

Neves (2004) acredita que o modelo de desenvolvimento pós II Guerra Mundial foi bem-sucedido no quesito aumento de riqueza e produção material, porém falhou na oferta de produtos de qualidade. Este modelo de desenvolvimento ficou conhecido como "Revolução Verde", e teve seu primórdio na década de 1960 no Brasil. Buscava-se elevar a produtividade das cultivares com a adaptação dos ambientes rurais e sua correção nutritiva pela fertilização sintética, bem como o controle das pragas e invasoras pelo uso de agrotóxicos (MATOS, 2011).

A Revolução Verde promoveu vários avanços científicos e tecnológicos no espaço rural, possibilitou o melhoramento genético das cultivares, diminuiu o tempo de trabalho para produção e trouxe maior rendimento na produção alimentícia. Para o alcance desse incremento produtivo, foram adotadas um conjunto de práticas agrícolas, chamadas de "pacotes tecnológicos", como: uso intensivo de fertilizantes químicos e agrotóxicos, maquinários, monoculturas e irrigação (WEID, 2005). A Revolução Verde foi responsável pela modernização do campo de maneira seletiva, pois se concretizou nas propriedades que tinham condições de bancar os custos do pacote tecnológico. Com ela mudam-se as formas de produzir e a relação com a natureza.

Por outro lado, esse modelo resultou em consequências negativas nas perspectivas ambiental e social (WEID, 2005). De acordo com Moreira (2000), as críticas ambientalistas, antagônicas a Revolução Verde, se desenvolveram em três 
direções no Brasil: a) crítica técnica - denominada "prudência ambiental", consequência da relação sociedade e natureza (poluição dos rios, o uso inadequado do solo, a perda de diversidade biológica e o envenenamento dos alimentos e seres vivos); b) social - refere-se a "esfera sociopolítica", resultante da modernização tecnológica e da concentração de terras nas mãos de poucos, que impulsionaram a exclusão social; e c) econômica - atrelada a crise do petróleo nos anos 1970, que provocou a elevação do preços dos pacotes tecnológicos.

Essas críticas estimularam o advento de modelos alternativos de produção, visão biossistêmica (visão sistêmica no contexto do indivíduo) e diversidade produtiva (MOREIRA, 2000). É possível citar, como exemplo, os seguintes modelos: agricultura orgânica, biológica, ecológica, biodinâmica, regenerativa, permacultura, entre outras, cada uma com suas especificidades, práticas e ideologias (CAPORAL, 2009). Dentre essas, a produção orgânica é o objeto deste estudo.

O movimento da agricultura orgânica iniciou-se na década de 1940, em reação ao uso crescente de fertilizantes e insumos químicos. Após um case de sucesso realizado pelo agrônomo Sir Albert Howard com adubação orgânica, foram desenvolvidos vários experimentos na Europa e na Índia, que se expandiram para outros continentes (SAMBUICHI et al., 2017). Foi uma resposta alternativa aos pacotes tecnológicos da Revolução Verde.

No Brasil, na década de 1970, a produção orgânica esteve atrelada aos movimentos filosóficos que defendiam o contato direto dos indivíduos com a terra, como forma alternativa de vida, em contraposição ao modelo agrícola da época. Essas atitudes estimularam a conscientização ecológica e a busca por alimentação mais saudável. Segundo Faveret Filho et al. (2002), na década de 1980 elevou-se a clientela, surgiram várias cooperativas de consumo e de produção e restaurantes que buscavam por esse tipo de produto. $O$ interesse pelo consumo de alimentos orgânicos vem aumentando sistematicamente em vários países (CRINNION, 2010), inclusive nos emergentes como China (LIN, ZHOU e MA, 2010) e Brasil (LUIZZI, FERREIRA e SCHNEIDER, 2016). 
Os alimentos orgânicos são aqueles que em sua produção baseiam-se em técnicas que não utilizam fertilizantes e insumos químicos, organismos geneticamente modificados, conservantes e aditivos, ou seja, "a ênfase da produção está direcionada ao uso de práticas de gestão e manejo do solo que levam em conta as condições regionais e a necessidade de adaptar localmente os sistemas de produção" (SOUSA et al., 2012, p. 513). Não basta apenas isso. Para ser considerado orgânico, o produto precisa ser certificado.

No Brasil, a Lei que trata das diretrizes da agricultura orgânica é a de $n^{\circ}$ 10.831, publicada em 23 de dezembro de 2003. Nela, essa forma produtiva é definida como um sistema agropecuário que visa a otimização dos recursos existentes em uma localidade, com utilização de técnicas e culturas inerentes a ela. Envolve, dentre outras, a erradicação dos insumos químicos, de materiais geneticamente modificados e o rompimento com a dependência de energia nãorenovável. Deste modo, acredita-se o alcance da sustentabilidade econômica e ecológica em sua totalidade (BRASIL, 2003).

Essa Lei foi regulamentada pelo Decreto $N^{\circ} 6.323$, de 27 de dezembro de 2007, que define certificação orgânica como:

[...] ato pelo qual um organismo de avaliação da conformidade credenciado dá garantia por escrito de que uma produção ou um processo claramente identificado foi metodicamente avaliado e está em conformidade com as normas de produção orgânica vigentes (BRASIL, 2007).

O mesmo Decreto, em seu artigo 29, institui o Sistema Brasileiro de Avaliação da Conformidade Orgânica (SisOrg), composto de pessoal indicado pelos órgãos da "administração pública federal e pelos organismos de avaliação da conformidade credenciados pelo Ministério da Agricultura, Pecuária e Abastecimento". Estabelece, no artigo 30, a identificação "por um selo único em todo o território nacional" (BRASIL, 2007).

A certificação, no Brasil, obedece aos padrões internacionais ditados pela Federação Internacional dos Movimentos de Agricultura Orgânica (IFOAM). O 
produtor orgânico deve estar inscrito no Cadastro Nacional de Produtores Orgânicos, a partir da certificação em uma das três formas: a) Certificação por Auditoria - o selo é concedido por um organismo certificador credenciado no MAPA (Ministério da Agricultura, Pecuária e Abastecimento); b) Sistema Participativo de Garantia - marcado pela confiabilidade e responsabilidade coletiva dos seus membros, mediada por um Organismo Participativo de Avaliação da Conformidade, credenciado pelo MAPA e c) Controle Social na Venda Direta - mediante vinculação a uma Organização de Controle Social, registrada no MAPA (grupo, associação, cooperativa ou consórcio) (SANTOS et al., 2017).

A certificação orgânica oferece como vantagens ao consumidor a certeza que está comprando um produto com atributos garantidos por uma entidade certificadora como ausência de transgenia nas sementes e de agrotóxicos no trato produtivo. Não significa que serão, necessariamente, frescos, já que essa condição depende do transporte, acondicionamento e tempo de exposição. Comparativamente aos alimentos convencionais, os orgânicos são considerados mais saudáveis, mais ricos em antioxidantes inibidores do câncer, de nutrientes e com baixíssimos ou nenhum nível de agrotóxicos (BARANSKI et al., 2014).

O produtor tem como trunfo de mercado um produto diferenciado, geralmente ligado a sustentabilidade nas suas múltiplas dimensões. Em pesquisa com agricultores orgânicos de Rio do Sul (SC), em 2016, Maas et al. (2018) observaram que esse tipo de produtor considera como vantagem produtiva, acima de tudo, "saúde e vida saudável", além do reconhecimento pela qualidade de seu produto. Dentre as maiores dificuldades apontaram a carência de mão de obra e o baixo nível de conhecimento de maior parte das pessoas sobre a produção orgânica (MAAS et al., 2018).

A certificação não é um processo muito simples de ser adquirida. Faz-se necessária uma série de protocolos que precisam ser cumpridos e podem se constituir em entraves no processo de certificação e na resistência das famílias agricultoras em aderir a esse sistema de produção. Existem variáveis intangíveis 
que corroboram para o sucesso ou fracasso das tentativas de formação de grupos de produtores orgânicos. Neste sentido, este estudo tem seu foco num grupo informal de agricultores familiares do assentamento rural 72 , localizado no município de Ladário/MS, na fronteira do Brasil com a Bolívia, que vivenciam a transição agroecológica com vistas a produção orgânica desde 2016. O processo de transformação resultou na criação de uma Organização de Controle Social (OCS) que se encontra na fase embrionária. As questões norteadoras da pesquisa foram: como as famílias componentes do Grupo veem a possibilidade de formação de uma OCS para venda como orgânico sem necessidade de certificação? Compreendem o processo? Acham essa mudança válida para sua forma de produção e comercialização?

Neste contexto, o presente artigo tem como objetivo relatar as percepções dos participantes do Grupo Bem-Estar na implementação da certificação orgânica em sua propriedade e discutir as dificuldades para sua efetivação.

Este trabalho foi organizado em quatro seções. Na primeira são apresentados os procedimentos metodológicos da pesquisa. Em seguida busca-se oferecer um panorama da certificação orgânica no estado de Mato Grosso do Sul, contexto deste estudo. Posteriormente, é apresentada uma discussão sobre o funcionamento das OCS na certificação orgânica e, por fim, são trazidos os resultados dos levantamentos de informações primárias para dar entendimento sobre o processo inicial de passagem da transição agroecológica para a produção orgânica do Grupo Bem-Estar.

\section{PROCEDIMENTOS DA PESQUISA}

Este trabalho é resultante de uma pesquisa qualitativa e descritiva de uma das etapas de um projeto de pesquisa do Núcleo de Estudos em Agroecologia e Produção Orgânica do Pantanal (NEAP). 
Utilizou-se de pesquisa bibliográfica para conceituar e debater as temáticas fundamentais deste artigo: certificação, produção orgânica, Revolução Verde e Organização de Controle Social. O levantamento de informações primárias se deu de duas formas: a) pela descrição dos processos desenvolvidos, das reações, sensações aparentes e das formas de expressão dos agricultores familiares durante as duas reuniões (novembro de 2019 e fevereiro de 2020) de criação da OCS do Grupo Bem-Estar - apoiou-se na técnica da observação; b) pela entrevista com as seis famílias agricultoras pertencentes a OCS - utilizou-se um roteiro de entrevista com questões o conhecimento de uma OCS e seu sistema de funcionamento, sobre as dificuldades e motivações de participação, o apoio recebido no processo e as percepções sobre a mudança do rótulo de produtor em transição agroecológica para orgânico pela venda direta via OCS.

Em ambas reuniões participaram, além das seis famílias agricultoras, pesquisadores e técnicos das instituições apoiadoras do Grupo Bem-Estar e da OCS: Empresa Brasileira de Pecuária Agropecuária (Embrapa Pantanal), Universidade Federal de Mato Grosso do Sul (UFMS, campus do Pantanal) e Agência de Desenvolvimento Agrário e Extensão Rural do Mato Grosso do Sul (AGRAER). Também, estiveram presentes bolsistas de Iniciação Científica e do Núcleo de Estudos em Agroecologia e Produção Orgânica do Pantanal (NEAP). As reuniões aconteceram em dois lotes de membros das famílias pertencentes à OCS no final de 2019 e início de 2020. Cada uma delas foi fotografada e os detalhes da discussão entre os apoiadores e as famílias foram anotadas num caderno de campo.

As entrevistas foram gravadas e aconteceram nos lotes de cada uma das seis famílias pertencentes à OCS na segunda quinzena do mês de abril de 2020 . Ocorreram duas simulações de visita de pares que foram, igualmente, fotografadas e descritas no caderno de campo. Os entrevistados foram denominados E1, E2, E3... E6, para preservar suas identidades.

As informações foram reunidas e analisadas na perspectiva da análise de conteúdo proposta por Bardin (2011) em três movimentos: pré-análise, exploração 
do material e tratamento dos resultados a partir da inferência e da interpretação. O primeiro movimento envolveu a organização das anotações das reuniões de um lado e das entrevistas transcritas de outro. Em seguida, partiu-se para a leitura flutuante, anotando as ideias mais repetidas e estabelecendo índices ou indicadores de comparação e análise. Depois buscou-se a codificação dos elementos analisados, sua classificação e categorização. Teve-se o cuidado de estabelecer na íntegra, ao longo do processo de categorização, a manutenção da fala dos entrevistados. Por fim, as questões utilizadas no roteiro são os elementos norteadores das inferências, interpretados à luz das teorias e conceitos trazidos neste trabalho.

\section{A CERTIFICAÇÃO ORGÂNICA NO ESTADO DE MATO GROSSO DO SUL}

O estado de Mato Grosso do Sul localiza-se na região Centro-Oeste do Brasil e possui uma extensão de 357.145,535 Km2. Conta com 79 municípios e tem sua economia fortemente apoiada na agricultura e na pecuária. O setor do comércio e serviços também encontra força nas quatro principais cidades sul-matogrossenses (Campo Grande, Dourados, Três Lagoas e Corumbá). O Estado detém o quarto maior rebanho bovino do Brasil, com destaque para a pecuária de corte, terceiro de cana-de-açúcar e milho e quinto de soja em grãos (IBGE, 2017). O Censo Agropecuário de 2017 contabilizou 43.223 estabelecimentos rurais (cerca de 30 hectares, em média) ligados a agricultura familiar no Estado (61\% dos ativos) (IBGE, 2017). Isso representa, caso bem trabalhado por políticas públicas, um quantitativo ótimo para a adoção de práticas coletivas em prol da certificação participativa.

Em 2019 o estado de Mato Grosso do Sul contava com 99 produtores orgânicos cadastrados no Ministério da Agricultura, Pecuária e Abastecimento (MAPA). Observou-se a materialização dos empreendimentos certificados em 17 
municípios (Gráfico 1) com os seguintes percentuais: a) 1,01\% em Bonito, Itaquirai, Mundo Novo, Rochedo e São Gabriel do Oeste; b) 2,02\% em Jaraguari, Maracaju, Naviraí, Nova Andradina, Rio Negro e Rio Verde de Mato Grosso; c) 5,05\% em Corumbá, Dourados e Ponta Porã; d) 7,07 em Terenos; e) 8,08\% em Ribas do Rio Pardo; e f) 52,53\% em Campo Grande (BRASIL, 2019).

Gráfico 1 - Empreendimentos com certificação orgânica por município no estado de Mato Grosso do Sul, Brasil, 2019

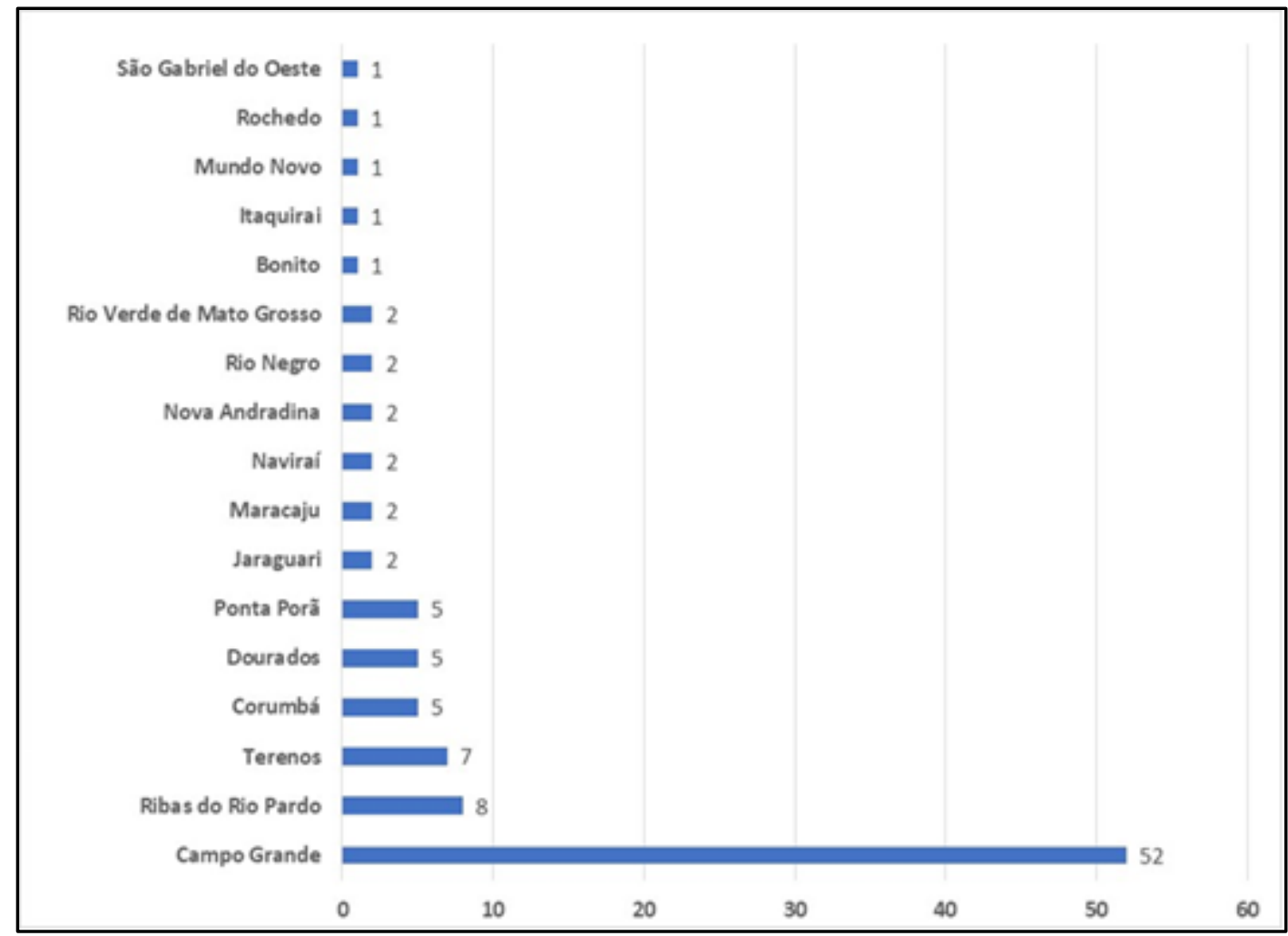

Fonte: MAPA (BRASIL, 2019): Organização dos autores.

O agricultor familiar é entendido, neste trabalho, em conformidade com a lei da Agricultura Familiar (BRASIL, 2006). Possui, como caraterísticas, a gestão e o emprego do trabalho familiar para as atividades econômicas de seu estabelecimento rural, com área máxima de 4 módulos fiscais. Em Mato Grosso do Sul, o maior módulo fiscal fica em Corumbá e corresponde a 110 hectares.

A avaliação dos sistemas orgânicos em Mato Grosso do Sul é processada através de duas formas de certificação: por Auditoria e pelo Sistema Participativo 
de Garantia (SPG), através de um Organismo Participativo de Avaliação da Qualidade Orgânica (OPAC). No primeiro tipo predominam duas certificadoras por auditoria: a Ecocert Brasil Certificações (57,58\%) e a IBD Certificações LTDA (30,30\%). São empresas que atuam em escala internacional, a primeira de origem francesa e a segunda, brasileira. Ambas totalizam $87,88 \%$, enquanto o segundo tipo, representado pela Rede Associação dos Produtores Orgânicos de Mato Grosso do Sul (APOMS), representa 12,12\% (Gráfico 2). O custo é pago pelo agricultor e varia conforme a complexidade do produto ou do coletivo de produtores. As certificadoras não uniformizam os valores, variando de 2 a 30 mil reais ao ano por estabelecimento rural.

Gráfico 2 - Organismos certificadores em quantidade de empreendimentos certificados no estado de Mato Grosso do Sul, Brasil, 2019

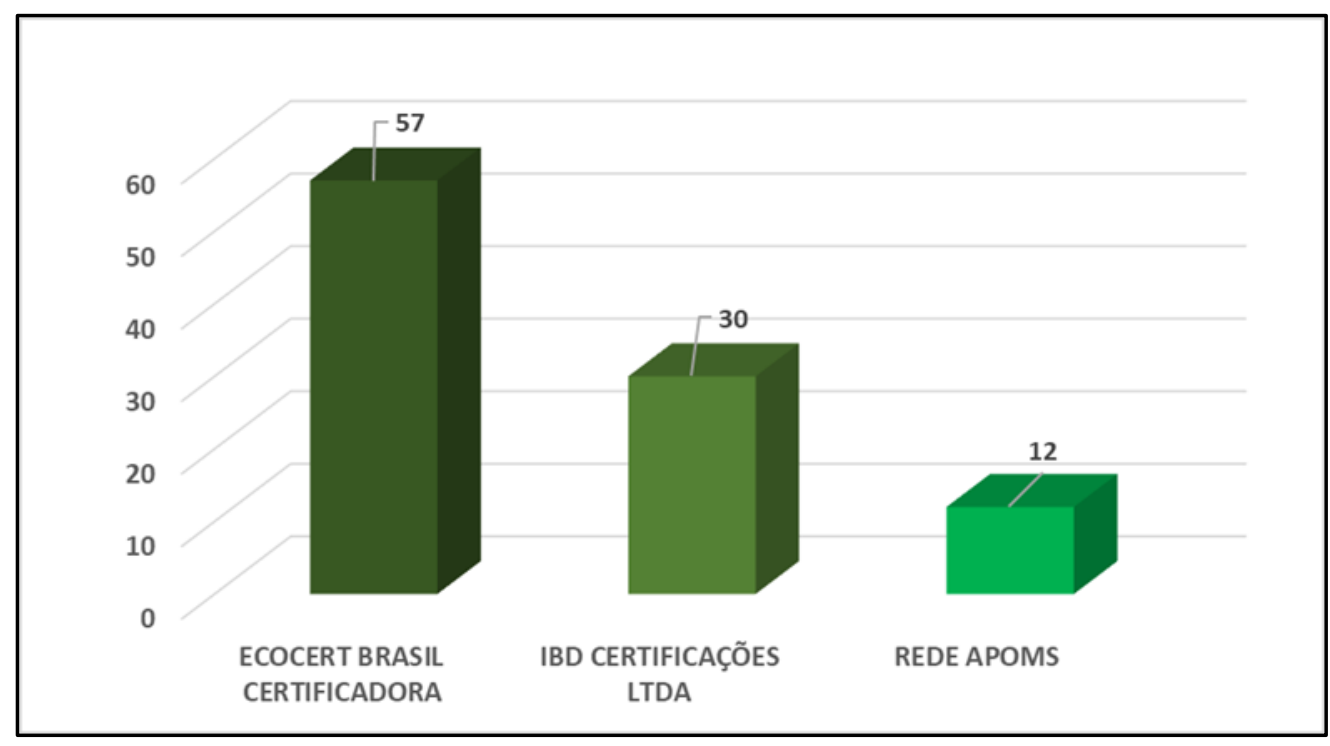

Fonte: MAPA (BRASIL, 2019): Organização dos autores.

Campo Grande é o município com maior número de produtores cadastrados em certificadoras no Mato Grosso do Sul, seguido por Ribas do Rio Pardo e Terenos, com 7. Neles predominam as certificadoras por auditoria. Em relação ao OPAC, observa-se a concentração no Sul do Estado, mais precisamente em quatro municípios: Dourados, Itaquirai, Mundo Novo e Ponta Porã. Isso pode estar 
relacionado ao fato de sua sede se localizar em Glória de Dourados. Por outro lado, as certificadoras por auditoria, IBD Certificações LTDA e Ecocert Brasil Certificadora, estão distribuídas sem uma aparente lógica territorial (Figura 1). Em escala nacional, de acordo com a pesquisa de Souza, Batista e Cesar (2019) realizada sobre os dados de 2016, essas duas empresas dominam mais de $90 \%$ das certificações por auditoria nas regiões Norte, Nordeste e Centro-Oeste, mais de 80\% do Sudeste e cerca de $70 \%$ da região Sul do Brasil.

Figura 1 - Densidade territorial de empreendimentos certificados como orgânicos por município em Mato Grosso do Sul, Brasil, 2019

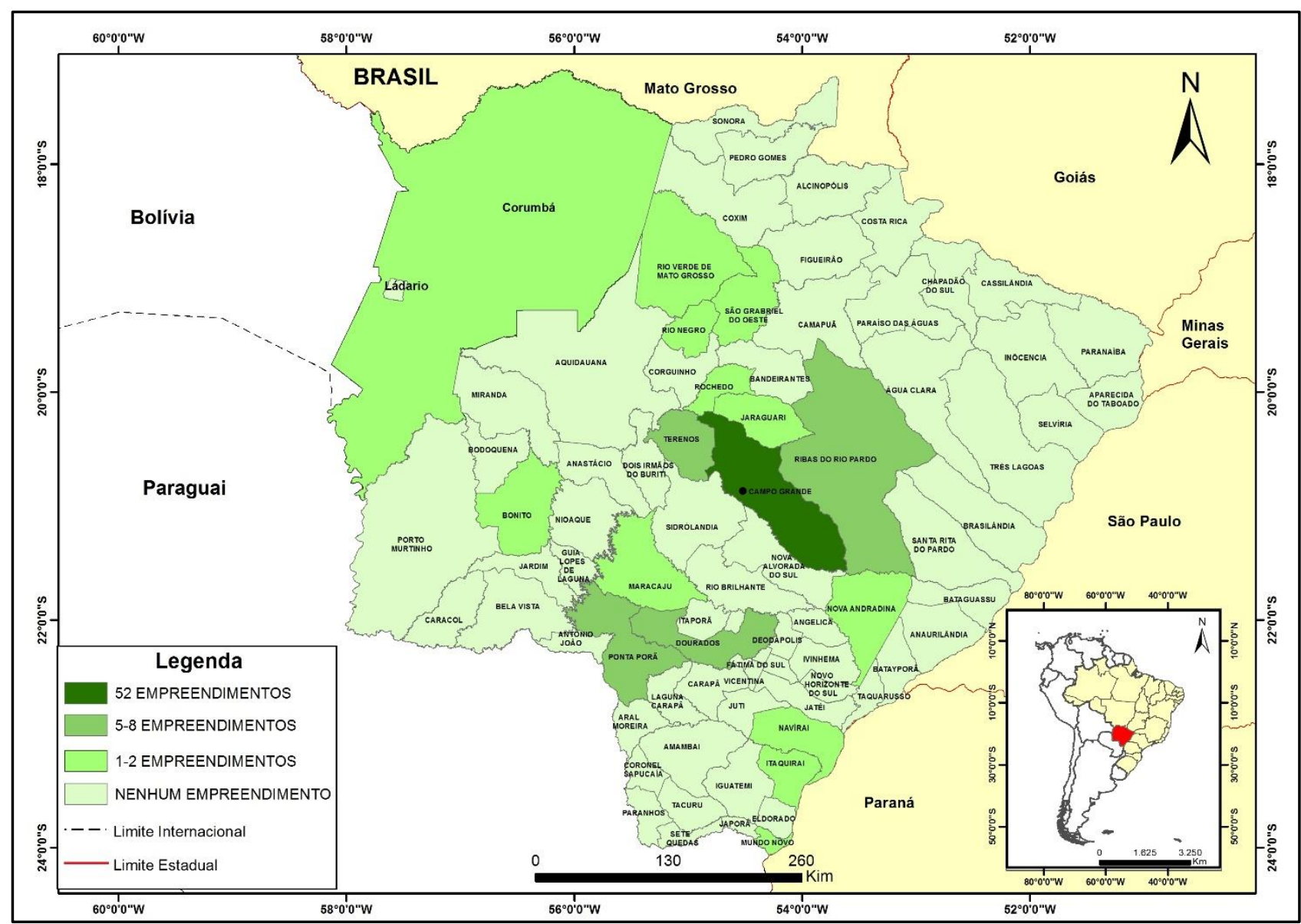

Fonte: MAPA (BRASIL, 2019): Organização dos autores.

Cabe destacar que o estado não dispõe de nenhuma certificação do tipo Organismo de Controle Social (OCS), apesar da previsão em Lei. As certificações por auditoria são predominantes no Brasil, apesar do maior crescimento 
percentual dos OPACs e das OCS (SOUZA, BATISTA E CESAR, 2019) nos anos mais recentes. Em pesquisa realizada referente aos anos de 2015 e 2018 no Cadastro Nacional de Produtores Orgânicos (CNPO) do Ministério da Agricultura, Pecuária e Abastecimento (MAPA), Galhardo, Silva e Lima (2018) perceberam esses mesmos indicadores e sinalizaram para a predominância de OCS em funcionamentos nos estados brasileiros de Alagoas, Amazonas, Espírito Santo, Mato Grosso, Paraíba, Pernambuco, Rio Grande do Norte, Rondônia, Roraima, Sergipe e São Paulo.

Em Mato Grosso do Sul predominam as certificações da Produção Primária Vegetal (PPV), que representam 72,73\% dos estabelecimentos certificados do Estado, seguida pela Produção Primária Animal (PPA), com 15,15\%. No município de Corumbá existem cinco empreendimentos certificados e todos eles são da PPA e relacionados a bovinos de corte (BRASIL, 2019).

Pode-se dizer que o estado de Mato Grosso do Sul está iniciando seu processo de certificação orgânica, quando comparado a estados como o Paraná, com 3.869, Rio Grande do Sul com 3.199, São Paulo com 2.372, Santa Catarina com 1.645 e Minas Gerais com 1.003 empreendimentos cadastrados, dentre outros. No contexto da região Centro-Oeste do Brasil, o estado fica atrás de todas as Unidades Federativas. Goiás possui 171, o Distrito Federal tem 266 e Mato Grosso 271 empreendimentos cadastrados como orgânicos (BRASIL, 2019). As razões desse baixo número de cadastros de orgânicos estão relacionadas ao processo histórico, das formas de ocupação e uso do solo, com predomínio de monoculturas para exportação e a criação de gado bovino de forma extensiva.

\section{O FUNCIONAMENTO DAS OCS NA CERTIFICAÇÃO ORGÂNICA}

A OCS é um jeito de se promover a certificação orgânica, na qual são as famílias agricultoras quem garantem a origem e qualidade dos produtos (MOREIRA e BECKER, 2018). De acordo com o Decreto № 6.323, de 27 de dezembro de 2007, uma OCS funciona com base num "processo organizado de geração de 
credibilidade a partir da interação de pessoas ou organizações, sustentado na participação, comprometimento, transparência e confiança, reconhecido pela sociedade" (BRASIL, 2007).

Nesse sentido, uma OCS está baseada naquilo que Fonseca (2005) chamou de convenções doméstico-cívicas. São relações baseadas na confiança e na fidelização, motivações estruturantes do circuito produtivo. Pozzebon, Rambo e Gazolla (2018, p. 407) observam que "a validação social se sobrepõe à validação legal, sendo vínculos morais vistos como garantia, colocando o aparato jurídico em segundo plano".

Marques, Gaspari e Almeida (2017, p. 553) indicam que a OCS é uma das formas de se reconhecer a produção orgânica na qual o "agricultor vende diretamente ao consumidor seus produtos ou os destina a mercados institucionais (neste caso, é possível obter uma majoração de 30\% no preço dos produtos fornecidos)". Os autores destacam que essa modalidade permite diferenciar esse tipo de produção da convencional e que os agricultores assumem um compromisso coletivo de garantir a qualidade da produção orgânica. Essa forma é extremamente interessante por reduzir imensamente os custos da família agricultora com a certificação orgânica ao tempo que a coloca em contato direto com o consumidor final.

Fundamentalmente, uma OCS funciona como promotora das chamadas cadeias curtas (vendas diretas ao consumidor final) de comercialização (SOUZA, BATISTA e CESAR, 2019). É um importante mecanismo que minimiza, mas não elimina, a figura do atravessador e, consequentemente, a usurpação da mais valia gerada pelo trabalho dos agricultores no momento da produção e extraída na etapa da circulação pelo capitalista, na forma de intermediário.

As feiras livres representam os principais canais dos circuitos (cadeias) curtos de comercialização. De acordo com Cassol e Schneider (2015), as feiras são capazes de oferecer produtos com preços comparativamente mais baixos que 0 comércio formal, pois, em muitos casos, evita a participação dos atravessadores, 
e, pelo mesmo motivo, podem gerar uma renda maior aos agricultores. Esses elementos somados à oferta de alimentos diversificados e frescos corroboram para a Segurança Alimentar e Nutricional (SAN) de consumidores e agricultores. É por isso que Pozzebon, Rambo e Gazolla (2018, p. 413) afirmam existir uma "relação sinérgica entre agricultura familiar, autoconsumo, cadeias curtas agroalimentares e SAN".

Existem algumas facilidades que os agricultores familiares podem acessar com a vinculação em uma OCS. Uma delas é a possibilidade de um produtor levar para a feira, por exemplo, um produto de seu vizinho, também vinculado na mesma. Basta, para tanto, identificar claramente de quem é o produto e estar pronto para esclarecimento de eventuais dúvidas sobre o processo de cultivo e de colheita (BRASIL, 2009).

A legislação brasileira considera que uma OCS pode ser composta de "um grupo, associação, cooperativa ou consórcio" de agricultores familiares, "com ou sem personalidade jurídica". Estabelece, ainda, que é fundamental existir entre seus membros relações que envolvam "organização, comprometimento e confiança" (BRASIL, 2009, p. 11).

Cabe a uma OCS a orientação de procedimentos a serem adotados pelos seus membros para cumprimento das regulações/normativas técnicas da produção orgânica. É desejado que a organização esteja articulada com a Comissão da Produção Orgânica (CPOrg) estadual para fins de esclarecimentos e apoio nos processos que garantam a venda dos produtos como orgânicos, sem a certificação (BRASIL, 2009).

Uma vez vinculada a uma OCS, seus membros devem garantir a visitação, em suas propriedades, dos consumidores, fiscais, escolas, enfim, de quaisquer interessados em conhecer os processos produtivos. Outro elemento trazido pela legislação é a necessidade de se fazer o cadastro da organização em uma Superintendência Federal de Agricultura, vinculada ao MAPA. Isso permite a 
rastreabilidade dos produtos em caso de dúvidas sobre sua qualidade e procedência (BRASIL, 2009).

O cadastramento de uma OCS é feito a partir da entrega dos seguintes documentos: formulário de cadastro, formulário com os dados de cada produtor, termo de responsabilidade solidária assinado pelos membros, indicação da forma de controle social do sistema produtivo e Declaração de Aptidão ao Pronaf (DAP) ativa de cada família agricultora (BRASIL, 2009).

A responsabilidade solidária é um compromisso firmado entre os membros de uma OCS para cumprimento das obrigações referentes à produção orgânica em que um assegura o outro, reafirmando princípios de confiança entre eles. Na mesma direção, um dos mecanismos de controle social é a visita de pares para acompanhamento dos sistemas agrícolas dos membros da organização (BRASIL, 2009).

Vale dizer que os produtos vendidos por uma OCS ativa perante o MAPA não podem utilizar o selo de produto orgânico, como as demais modalidades certificadoras. A legislação permite apenas a utilização da seguinte expressão em seu ponto de venda - uma feira, por exemplo: “Produto orgânico para venda direta por agricultores familiares organizados, não sujeito à certificação, de acordo com a Lei n. 10.831, de 23 de setembro de 2003" (BRASIL, 2009).

\section{FORMAÇÃO DA ORGANIZAÇÃO DE CONTROLE SOCIAL (OCS) DO GRUPO BEM-ESTAR}

O Grupo informal de produtores em transição agroecológica Bem-Estar é constituído por oito famílias que residem no assentamento 72 , localizado no município de Ladário, na porção Oeste do Mato Grosso do Sul (Figura 2). Com 340 km² de extensão territorial (IBGE, 2019), o município é um enclave territorial por estar dentro do espaço geográfico de Corumbá (SILVA, 2019). 
16 | Transição para a produção orgânica via Organização de Controle Social do Grupo Bem-Estar, Ladário-MS

Figura 2 - Localização geográfica do município de Ladário-MS

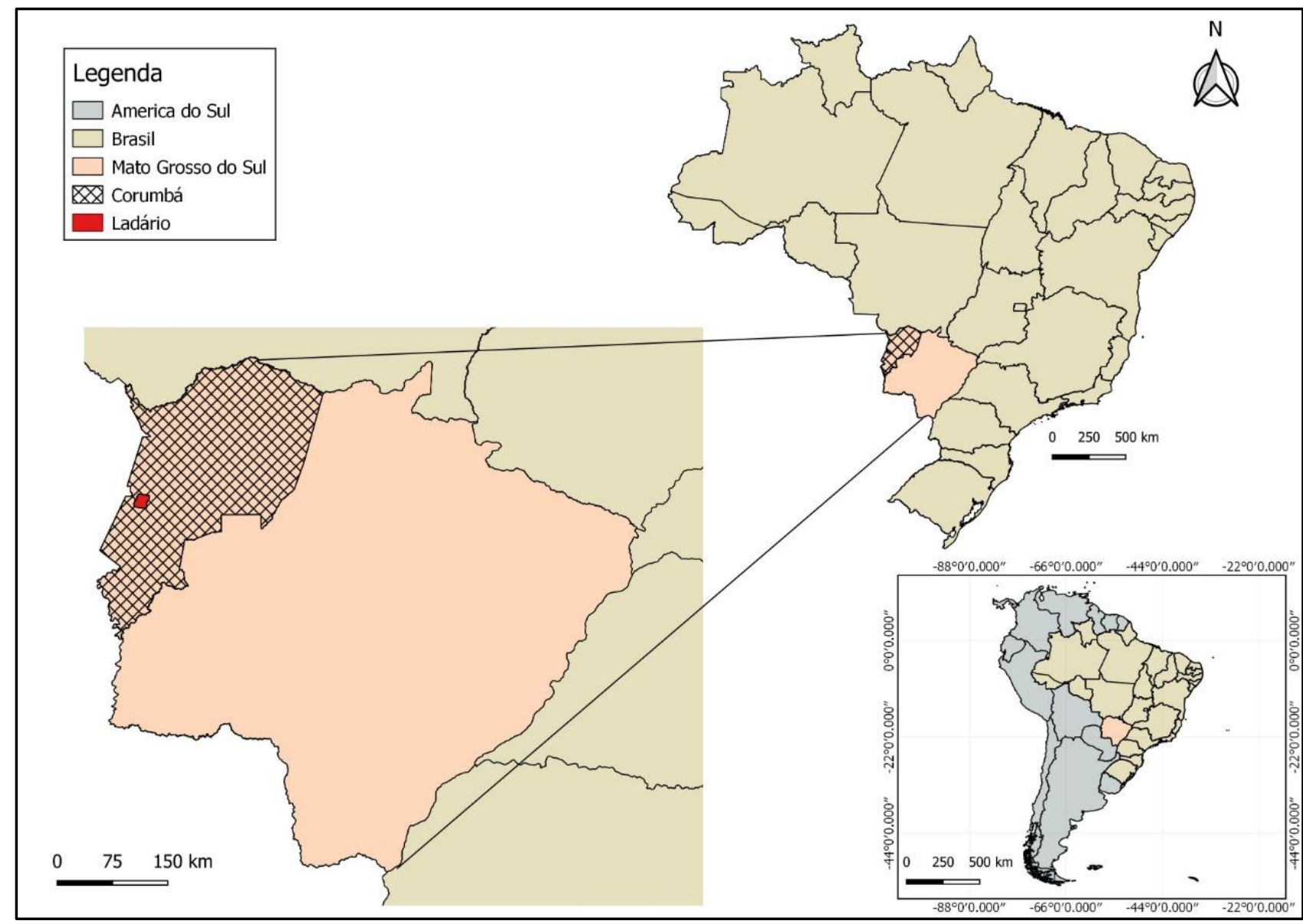

Fonte: Autores/as (2021).

O assentamento 72 fica a $5 \mathrm{~km}$ da área urbana de Ladário, nas proximidades da APA Baia Negra, que o conecta ao Pantanal Sul-mato-grossense (Figura 3). Foi criado em 1998 pelo Instituto Nacional de Colonização e Reforma Agrária (INCRA), oriundo da Fazenda Primavera, totalizando uma área de 2.341,2996 hectares (COSTA, ZARATE e MACEDO, 2012). 
Figura 3 - Localização do assentamento 72

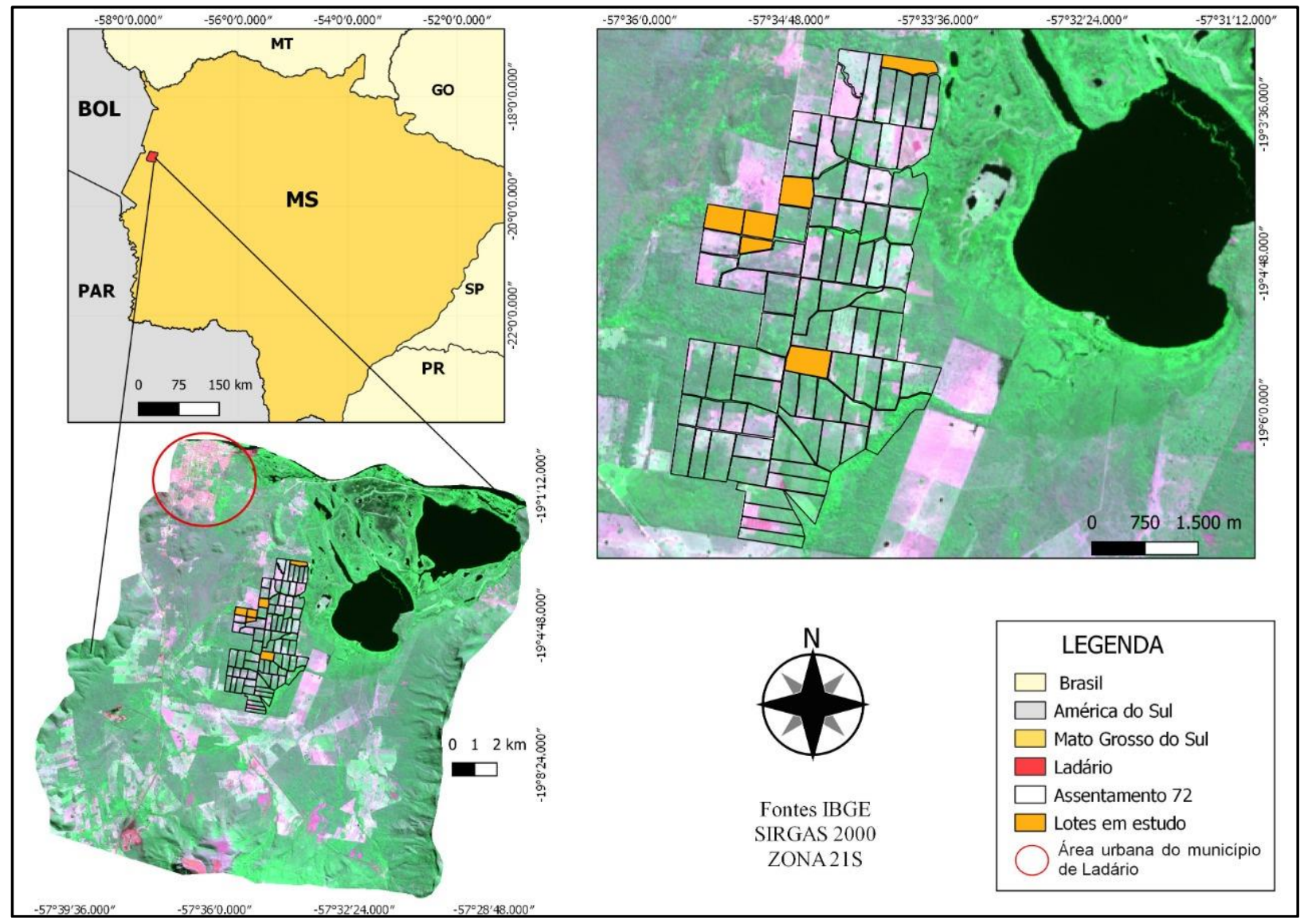

Fonte: Autores/as (2021).

O grupo Bem-Estar tem sua origem embrionária em 2011, com um projeto de pesquisa com apoio financeiro do CNPq, intitulado "Alternativas para o desenvolvimento territorial rural do assentamento 72 em Ladário-MS, na região do Pantanal", executado no âmbito da Universidade Federal de Mato Grosso do Sul (UFMS) e com a parceria de pesquisadores da Embrapa Pantanal. A potencialização da produção das famílias do assentamento se deu com a introdução de alternativas em bases agroecológicas (PERON, COSTA e ARRUDA, 2018).

Em 2015 foi criado o Grupo Bem-Estar com a proposta de comercialização dos produtos em transição agroecológica para venda direta nas feiras e para instituições públicas (PERON, COSTA e ARRUDA, 2018). No início, o principal objetivo foi a implementação da produção de hortaliças em bases agroecológicas para, posteriormente, converter o Grupo em uma OCS para venda direta sem certificação e, por fim, transformá-lo em um núcleo da certificadora participativa 
da APOMS (DI FÁBIO, COSTA, FEIDEN, 2017). Para isso, o grupo foi inserido, em 2018, no Núcleo de Estudos em Agroecologia e Produção Orgânica do Pantanal (NEAP).

No final de 2019 e início de 2020 foi iniciado o processo de criação de uma OCS no contexto do Grupo Bem-Estar, envolvendo seis das oito famílias que se mostraram interessadas em avançar no processo de reconhecimento como produtores orgânicos. No dia 20 novembro de 2019, no Assentamento 72, no lote de uma das famílias (lote de E1) ocorreu a primeira reunião do Grupo Bem-Estar com os produtores, e teve como pauta dois pontos relevantes: a) eleição da nova coordenação do Grupo Bem-Estar; e b) apresentação sobre a conversão do Grupo Bem-Estar em uma Organização de Controle Social.

Algumas mudanças são geradoras de incertezas. No caso, foi possível perceber algumas estranhezas demonstradas pelos participantes da reunião, que apresentavam expressões de dúvidas estampadas no rosto, mas sem expressar reprovação perante o projeto. Favero e Sarriera (2009), a partir de um estudo argumentativo com os resultados do seminário em comemoração aos 30 anos do curso de pós-graduação em Extensão Rural da Universidade Federal de Santa Maria (UFSM) em novembro de 2005, perceberam as dificuldades de introduzir elementos inovadores nas famílias rurais. Como o mundo rural se apresenta de maneira diferenciada, são exigidos métodos próprios para interpretação da realidade. Depreende-se de suas análises a dificuldade da indução de inovações tecnológicas para os camponeses.

O processo se deu da seguinte forma: a) existia um acordo inicial para avançar da transição agroecológica para a produção orgânica; b) um dos pesquisadores do NEAP apresentou as possibilidades para a realização do processo de certificação via OCS; c) abriu-se espaço para questões e foi indagado: "qual o benefício desta certificação para minha propriedade?" e "conseguirei abrir novos caminhos para comercialização?"; d) ocorreu a entrega da cartilha do MAPA 
“Controle Social na venda direta ao consumidor de produtos orgânicos sem certificação"; e) um dos pesquisadores do NEAP realizou a leitura da cartilha, acompanhada pelos presentes; e f) buscou-se a orientação dos agricultores e esclarecimentos de suas dúvidas.

Após os procedimentos esclarecedores sobre o funcionamento, benefícios e regulamentação desta forma de certificação, foi possível observar tímidos sorrisos das faces das famílias agricultoras. A sensação de afeição a proposta era esperada, pois há 10 anos os pesquisadores pertencentes ao NEAP desenvolvem projetos de alternativas produtivas para essas famílias. A confiança é um dos elementos fundamentais da extensão rural (FAVERO e SARRIERA, 2009; CAPORAL, 2009).

Em seguida foi iniciada a simulação da visita de pares para verificação de conformidade dos lotes, conforme prevê os mecanismos de controle para garantia orgânica. Foram observadas algumas situações, como por exemplo: as condições de limpeza da casa, dos banheiros, a existência ou não de fossas sépticas, os cuidados com o lixo (disposição e destinação dos resíduos sólidos e material orgânico), a presença e cercamento de animais domésticos, os tipos e os sistemas de cultivo, presença ou não de sistemas de irrigação, uso da água, adubação verde, quebra-ventos, dentre outros. Maas et al. (2018) consideram que a visita de pares cria uma sinergia entre os agricultores, resultante da troca de experiências, e amplia a confiança no processo produtivo.

A reunião do dia 20 de fevereiro de 2020 foi realizada em outro lote (de E2), com o objetivo de afinar as intencionalidades e avançar para a formação da OCS. Os agricultores se mostraram relativamente resistentes ao processo de adesão à OCS apesar de, ao mesmo tempo, demonstrar interesse pela iniciativa. Essa dúvida aparente estimulou a realização de uma investigação in loco para compreensão das intencionalidades em torno da criação de uma OCS, cujos resultados são descritos a seguir.

Percebeu-se que os entrevistados conferem elevada importância subjetiva ao se perceberem como parte de uma Organização de Controle Social (OCS) com 
20 | Transição para a produção orgânica via Organização de Controle Social do Grupo Bem-Estar, Ladário-MS

fins de venda direta aos consumidores na condição de produtores orgânicos. Todos indicaram nota de importância máxima ao quesito satisfação pessoal e somente um deles não atribuiu dez ao reconhecimento (Quadro 1). Acreditava-se que o quesito "venda" seria, naturalmente, o mais valorizado, porém foi o que apresentou menor importância para eles.

Quadro 1 - Percepção sobre o grau de importância atribuído pelas famílias produtoras, segundo critérios estipulados para estar numa OCS

\begin{tabular}{|c|c|c|c|c|}
\hline \multirow{2}{*}{ Entrevistados } & \multicolumn{4}{|c|}{ Escore de importância (0 = Nenhuma; 10 = Máxima) } \\
\cline { 2 - 5 } & Produção & Reconhecimento & Venda & Satisfação Pessoal \\
\hline E1 & 10 & 10 & 7 & 10 \\
\hline E2 & 9 & 10 & 8 & 10 \\
\hline E3 & 9 & 10 & 9 & 10 \\
\hline E4 & 10 & 10 & 9 & 10 \\
\hline E5 & 8 & 9 & 7 & 10 \\
\hline E6 & 10 & 10 & 10 & 10 \\
\hline
\end{tabular}

Fonte: Trabalho de campo, 2020: Organização dos autores.

Quando questionados sobre a razão da menor importância atribuída às vendas, destacaram que a principal dificuldade é a concorrência com outros produtos oferecidos nas feiras. São produzidos de forma convencional e chegam ao consumidor final com preço inferior. Ponderam que existe uma clientela específica para seus produtos e isso facilita suas vendas. As feiras organizadas pelo NEAP são exclusivas para eles e, por isso, a concorrência é relativizada. Nas palavras de um entrevistado:

Acredito que não conseguiríamos agregar valor ao produto com esta certificação. Apenas em determinados locais, como UFMS, Embrapa e Agraer, pois o público busca por produtos que apresentam qualidade, e por terem a confiança que o produto é orgânico, não o valor. Já nas feiras livres, por conta da concorrência, nunca iremos conseguir, pois o público busca o valor mais barato, não a qualidade. Acredito que minha produção possa aumentar e o Grupo Bem-Estar iria se unir mais. Queremos que o público de fora dê valor, também, ao produto; que reconheçam a importância do produto orgânico (Informação oral - E1). 
Estudando as dificuldades e avanços conquistados nos processos de certificação da Rede de Agroecologia APOMS, Padovan (2016) identificou resultados semelhantes. Embora os agricultores se mostraram cientes dos processos e das práticas agroecológicas, a comercialização dos seus produtos encontra barreiras na sua valorização. O estudo realizado na porção meridional do Mato Grosso do Sul inclui a logística como entraves nas vendas.

Outra possível explicação é a não compreensão plena do que é uma OCS e suas finalidades pelos agricultores. Quando solicitados para dizer o que seria uma OCS, as respostas não refletiram o conhecimento adequado do tema (Quadro 2). Destacadamente dois não souberam dizer. Três deles apresentaram elementos parciais de uma OCS em suas respostas: "organizar as coisas do plantio, da colheita, tudo que o Grupo já faz (E1)"; "é como você mexe com a sociedade para venda direta, mostrar o que você vende, plantar aquilo que o mercado necessita" (E3); e "é quando os indivíduos têm uma mesma ideia no grupo pra melhorar a sociedade" (E4).

Quadro 2 - Questões sobre o conhecimento OCS pelas famílias produtoras, segundo critérios estipulados

\begin{tabular}{|l|c|c|c|c|c|c|}
\hline \multicolumn{1}{|c|}{ Questões sobre OCS } & \multicolumn{6}{c|}{ Entrevistados } \\
\cline { 2 - 8 } & E1 & E2 & E3 & E4 & E5 & E6 \\
\hline Sabe o que é uma OCS? & Sim & Não & Sim & Não & Sim & Sim \\
\hline Acha importante a criação de uma OCS? & Sim & Sim & Sim & Sim & Sim & Sim \\
\hline $\begin{array}{l}\text { Se não tivesse o apoio do NEAP você teria entrado } \\
\text { na OCS? }\end{array}$ & Não & Não & Não & Não & Não & Não \\
\hline Acha interessante a visita de pares? & Sim & Sim & Sim & Sim & Sim & Sim \\
\hline $\begin{array}{l}\text { Acha que é válida a mudança do rótulo do } \\
\text { produtor em transição agroecológica para orgânico } \\
\text { pela venda direta via OCS? }\end{array}$ & Sim & Sim & Sim & Sim & Sim & Sim \\
\hline $\begin{array}{l}\text { Conhece todas as etapas necessárias para o } \\
\text { funcionamento da OCS? }\end{array}$ & Não & Não & Sim & Não & Não & Sim \\
\hline
\end{tabular}

Fonte: Trabalho de campo, 2020: Organização dos autores. 
Uma resposta foi protocolar: "essa organização me fornece um documento que me dá a conformidade de produção orgânica participativa. Através desse documento, que tem todas as informações, é possível fazer uma busca no MAPA" (E.6). Essa resposta foi retirada da cartilha "Controle social na venda direta ao consumidor de produtos orgânicos sem certificação" (BRASIL, 2009). O material foi trabalhado nas reuniões do grupo Bem-Estar. Essa foi a única entrevista feita por telefone, pois já tinha iniciado o período de isolamento social motivado pela pandemia da covid-19. Percebe-se, pois, a necessidade de maiores esclarecimentos aos participantes do grupo sobre o que é uma OCS.

Apesar de todos entenderem a importância da OCS para o Grupo, as respostas não justificam tal percepção. Dois entrevistados não souberam responder o porquê da relevância para o grupo. Uma das respostas apontou para ajuda na diversificação da produção: "é importante para levar variedades para a população. Isso ajuda diminuir a concorrência entre os próprios membros do grupo, o que levaria a um excesso de certos produtos e ausência de outros, fazendo a clientela buscar produtos convencionais" (E1).

Ainda sobre a questão, um dos produtores apontou para a rastreabilidade, no sentido de facilitar a identificação da origem do produto como principal razão de uma OCS (E6). Outro acenou para a relativização de sua importância: "no final das contas, o que define a compra é o preço" (E2). A importância dos preços nas feiras livres de Ladário, onde alguns desses agricultores familiares comercializam seus produtos, já tinha sido observado em outro estudo (KUKIEL, CUYATE e COSTA, 2012).

Um dos entrevistados atribuiu a credibilidade na hora da venda: "ela serve para garantir a não utilização de agrotóxicos na produção" (E3). A obtenção da certificação é uma garantia ao consumidor que o processo produtivo acompanhou todas as etapas determinadas pela lei para o sistema orgânico e configura-se como uma vantagem para os agricultores familiares (VRIESMAN et al., 2012). 
Todos acreditam que a mudança do rótulo de produto em transição agroecológico para orgânico funciona como um diferencial e pode agregar valor no produto. A preocupação reside nos procedimentos burocráticos que devem ser adotados para validação desse mecanismo. As anotações, discutidas mais adiante, são verdadeiros tormentos na cabeça dos agricultores.

Quando questionados sobre o apoio do Núcleo de Estudos em Agroecologia do Pantanal (NEAP) e a sua importância para adesão à OCS, os entrevistados afirmaram, unanimemente, a impossibilidade de conseguirem sozinhos. Apontaram que sem o suporte e o acompanhamento do NEAP não seria possível a efetivação da organização. As principais dificuldades são o conhecimento parcial sobre os procedimentos técnicos do cultivo orgânico e desconhecimento sobre esse tipo de certificação e dos procedimentos exigidos pela legislação para obtêla. O papel do Núcleo de Agroecologia é enaltecido em uma das falas: “O papel do núcleo vai muito além desse apoio. Eles atuam, também, para integrar a gente enquanto produtores. A gente agia sem o espírito de grupo e com isso estamos fortalecendo com a OCS" (E3).

Em contrapartida, quando perguntados se continuariam na OCS mesmo sem a ajuda do grupo, todos responderam que sim. A justificativa é o entendimento que o grupo está fortalecido e experiente nas práticas de produção e comercialização.

Cabe destacar que essa suposta autonomia não é verdadeira. Eles dependem do Núcleo para indicar os próximos passos em cada etapa produtiva rumo à certificação orgânica. Quando questionados em qual etapa se encontram para consolidação da OCS, apenas um entrevistado tentou responder: "estamos esperando completar os anos que faltam para visita da OCS, porém, não foram concluídas todas as etapas" (E6). Observa-se que a resposta não indica as etapas cumpridas e, tampouco, o estágio em que se encontram.

Para efetivação de uma OCS é preciso que seja seguidas as seguintes etapas: a) estabelecer um plano de manejo para cada unidade produtiva; b) preencher um 
formulário contendo os dados e solicitações; c) criar um plano descritivo contendo dados sobre a produção e comercialização; e d) assinalar um termo de compromisso. Após esses procedimentos, uma declaração será emitida, devendo estar visível e disponível na hora da venda direta (PIZZAIA et al., 2018). Com o apoio do NEAP, já foram cumpridas todas as etapas, restando tão somente a assinatura do termo de compromisso, que ficou paralisado desde abril de 2020 por conta do confinamento social motivado pela covid-19.

Em relação às dificuldades para estar em uma OCS, foram apresentados aos agricultores entrevistados cinco elementos: as anotações das informações, a visita de pares, a comercialização, produção e divulgação (Quadro 3). Todos apontaram escore máximo de dificuldade para as anotações e nenhum para a divulgação.

Quadro 3 - Percepção sobre o grau de dificuldade para estar em uma OCS pelas famílias produtoras, segundo critérios estipulados

\begin{tabular}{|c|c|c|c|c|c|}
\hline \multirow{2}{*}{ Entrevistados } & \multicolumn{5}{|c|}{ Escore de dificuldades (0 = Nenhuma; 10 = Máxima) } \\
\cline { 2 - 6 } & $\begin{array}{c}\text { Anotações das } \\
\text { informações }\end{array}$ & $\begin{array}{c}\text { Visita de } \\
\text { pares }\end{array}$ & Comercialização & Produção & Divulgação \\
\hline E1 & 10 & 6 & 8 & 8 & 0 \\
\hline E2 & 10 & 5 & 8 & 10 & 0 \\
\hline E3 & 10 & 5 & 7 & 10 & 0 \\
\hline E4 & 10 & 6 & 6 & 8 & 0 \\
\hline E5 & 10 & 6 & 8 & 9 & 0 \\
\hline E6 & 10 & 5 & 8 & 9 \\
\hline
\end{tabular}

Fonte: Trabalho de campo, 2020: Organização dos autores.

A Instrução Normativa (IN) 46, em seu artigo $7^{\circ}$ do capítulo II, que trata da documentação e do registro, indica a obrigatoriedade de anotação de todas as operações realizadas na propriedade rural, desde a aquisição dos insumos até a comercialização dos produtos (BRASIL, 2011). Parte da dificuldade dos agricultores é explicada pelo baixo grau de escolaridade e pela escassez de mão de obra. Alegam não conseguir conciliar todas essas atividades e a anotação é vista por eles 
como mais difícil que a própria produção. Estudando os entraves para a certificação orgânica do leite em 73 propriedades de agricultores familiares no Oeste catarinense, Frison e Rover (2014) encontraram resultados semelhantes. Para eles, a resistência às anotações é um dado cultural dos camponeses. Pinheiro (2012) encontrou os mesmos resultados ao analisar agricultores familiares do município de Palmeira-PR.

O inciso XIII do art. $2^{\circ}$ da IN 19, de 28 de maio de 2009, apresenta os mecanismos de controle e informação da qualidade orgânica e conceitua a visita de pares como um requisito de avaliação aos cumprimentos das práticas e critérios de produção pelos membros do grupo (BRASIL, 2009). Para os entrevistados a visita de pares não é algo complicado e não se configura como problema. Acreditam que se trata de uma oportunidade para compartilhar experiências e trocar ideias com as realidades vivenciadas em cada propriedade, aproximando dos resultados apresentados por Maas et al. (2018). Nas palavras de um deles: "as visitas permitem que, através das trocas de experiências, a gente possa avaliar os próprios erros e acertos" (E2).

A comercialização tem suas dificuldades relativizadas por conta do apoio que recebem do NEAP. Destacam a relevância das feiras agroecológicas que acontecem nas instituições parceiras (campus do Pantanal da Universidade Federal de Mato Grosso do Sul, Campus de Corumbá do Instituto Federal de Mato Grosso do Sul e Embrapa Pantanal). Destacaram problemas para acessar novos mercados, como os programas de governo (PNAE e PAA), muito mais pela baixa produção que, propriamente por entraves burocráticos.

A orientação dos Núcleos de Agroecologia (NEA) é fundamental para grupos de agricultores familiares em transição agroecológica ou certificados como orgânicos pela venda direta e pelos sistemas participativos. Haas, Rambo e Bolter (2019) demonstram que a maioria dos NEA estão nas universidades e institutos federais. Existem vários exemplos de apoio à comercialização de produtos agroecológicos, como as feiras promovidas pela Associação dos Agricultores 
Familiares do Assentamento "20 de Março" no campus de Três Lagoas da UFMS e no Condomínio Don El Chall, na mesma cidade estudadas por Pinha e Almeida (2018), e os esquemas de venda com o uso do Google Docs do NEA Litoral Norte, do campus Litoral da Universidade Federal do Rio Grande do Sul (UFRGS), descritos por Haas, Rambo e Bolter (2019).

A produção é considerada a segunda maior dificuldade na ordem de importância dada pelos entrevistados. Afirmam que as condições climáticas de boa parte do ano (seis meses quentes e secos), o difícil acesso a água e infraestrutura dificultam o trabalho na produção. Apesar da capacitação realizada pelo NEAP alguns agricultores não se sentem totalmente seguros para a produção em bases agroecológicas. Na fala de um deles é possível confirmar essa constatação: “minha dificuldade é o controle das pragas e o manejo das caldas. Acho que me falta experiência e conhecimento técnico para utilizar da forma correta e algumas pragas específicas. Muitas delas já sei combater, mas ainda tem umas complicadas" (E4).

Os levantamentos realizados permitiram ver que uma OCS pode ser uma resposta menos custosa e interessante para os produtores entregarem seus produtos como orgânicos através dos circuitos curtos de comercialização. Ainda assim existem obstáculos fortemente solidificados na cultura camponesa de fazer anotações de seus afazeres. A confiança é um elemento da lida cotidiana deles. Os resultados servem para produzir uma inquietação nos núcleos de agroecologia que apoiam a passagem para a agricultura orgânica na direção de atentar para não permitir que seus desejos são maiores que os das famílias apoiadas. Não se pode perder de vista que elas são, em última instância, o foco dos resultados e não os projetos dos pesquisadores. 


\section{CONSIDERAÇÕES FINAIS}

O estudo das percepções de agricultores familiares do Grupo Bem-Estar sobre a passagem da transição agroecológica para a produção orgânica via Organização de Controle Social demonstrou a importância da participação dos Núcleos de Estudos em Agroecologia e Produção Orgânica (NEAs) na orientação e apoio da produção e comercialização. É preciso tranquilidade na orientação para não apressar os passos de famílias que funcionam numa lógica camponesa, de sobrevivência e não de mercado, mesmo estando nele, para certificação orgânica.

É preciso criar mecanismos de empoderamento das famílias agricultoras. Mas isso não significa abandoná-los a partir de sua suposta emancipação. A orientação para o enfrentamento das lógicas de mercado deve ser continuada, pois são dinâmicas. As anotações das informações não é algo entendido pelos agricultores familiares como necessário. Para eles, a confiança no apalavramento é parte da cultura e dispensa registro. Este é, seguramente, um dos entraves na passagem para a produção orgânica desse tipo de agricultores, que carece de mais estudos e alternativas. Valorizar o saber camponês e estimular o seu entrelaçamento com as inovações é o caminho para a extensão universitária e governamental conseguir ajudar essa forma de produção no rural brasileiro.

\section{AGRADECIMENTOS}

Os pesquisadores agradecem ao Conselho Nacional de Desenvolvimento Científico e Tecnológico (CNPq), pelo apoio Financeiro ao Projeto Processo: 402737/2017-2, intitulado “Núcleo de Estudos em Agroecologia e Produção Orgânica do Pantanal", da Chamada № 21/2016 - Linha 1: Criação de Núcleo de Estudo em Agroecologia e Produção Orgânica (NEA); e pela bolsa de Iniciação Científica (Pibic, 2019/2020). 
À Universidade Federal de Mato Grosso do Sul pelo apoio à pesquisa desenvolvida.

\section{REFERÊNCIAS}

BARANSKI, M. et al. Higher antioxidant and lower cadmium concentrations and lower incidence of pesticide residues in organically grown crops: a systematic literature review and metaanalyses. British Journal of Nutrition, v. 112, p. 794-811, jul. 2014. Disponível em: https://pubmed.ncbi.nlm.nih.gov/24968103. Acesso em: 24 fev. 2020 . doi: $10.1017 / S 0007114514001366$.

BARDIN, L. Análise de conteúdo. São Paulo: Edições 70, 2011.

BRASIL. Ministério da Agricultura, Pecuária e Abastecimento. Lei № 10831, de 23 de dezembro de 2003. Brasília: Diário Oficial da União, 2003, Seção 1, Página 8. Disponível em: http://www.planalto.gov.br/ccivil_03/leis/2003//10.831.htm. Acesso em: 04 abr. 2020.

BRASIL. Ministério da Agricultura, Pecuária e Abastecimento. Lei № 11.326, de 24 de julho de 2006. Brasília: Diário Oficial da União, 2006. Seção 1, de 25 jul. 2006. Página 1. Disponível em: http://www.planalto.gov.br/ccivil_03/_ato2004-2006/2006/lei/111326.htm. Acesso em: 19 nov. 2021.

BRASIL. Ministério da Agricultura, Pecuária e Abastecimento. Decreto № 6.323, de 27 de dezembro de 2007. Brasília: Diário Oficial da União, 2007. Seção 1, Páginas 2 a 8. Disponível em: http://www.planalto.gov.br/ccivil_03/_Ato2007-2010/2007/Decreto/D6323.htm. Acesso em: 04 abr. 2020.

BRASIL. Ministério da Agricultura, Pecuária e Abastecimento. Controle social na venda direta ao consumidor de produtos orgânicos sem certificação. Brasília: Mapa/ACS, 2009.

BRASIL. Ministério da Agricultura, Pecuária e Abastecimento. Instrução Normativa n. 46. Estabelece o Regulamento Técnico para os Sistemas Orgânicos de Produção Animal e Vegetal. Brasília: Mapa, 2011. Disponível em: https://www.jusbrasil.com.br/diarios/DOU/2011/10/07. Acesso em: 04 abr. 2020.

BRASIL. Ministério da Agricultura, Pecuária e Abastecimento. Cadastro Nacional de Produtores Orgânicos. Brasília: Mapa, 2019. Disponível em: https://www.gov.br/agricultura/pt-br/assuntos/sustentabilidade/organicos/cadastro-nacionalprodutores-organicos. Acesso em: 04 abr. 2020.

CAPORAL, F. R. Agroecologia: uma nova ciência para apoiar a transição a agriculturas mais sustentáveis. Brasília: MDA/SAF, v. 1, 2009. 
CASSOL, A.; SCHNEIDER, S. Produção e consumo de alimentos: novas redes e atores. Lua Nova, São Paulo, n. 95, p. 143-177, 2015. Disponível em: https://www.scielo.br/pdf/In/n95/0102-6445In-95-00143.pdf. Acesso em: 02 fev. 2020.

COSTA, E. A.; ZARATE, S. S.; MACEDO, H. A. Principiar do desenvolvimento territorial no assentamento rural 72, em Ladário-MS, Brasil. In: SAQUET, M. A. et al. Geografia da e para a cooperação ao desenvolvimento territorial: experiências brasileiras e italianas. São Paulo: Editora Outras Expressões, 2012, p. 125-145.

CRINNION, W.J. Organic foods contain higher levels of certain nutrients, lower levels of pesticides, and may provide health benefits for the consumer. Alternative Medicine Review, v. $15, \quad$ n. $1, \quad$ p. 4-12, 2010. Disponível em: http://www.altmedrev.com/archive/publications/15/1/4.pdf. Acesso em: 03 mar. 2020.

DI FÁBIO, E.; COSTA, E. A.; FEIDEN, A. Comercialização de produtos em transição agroecológica dos camponeses do grupo bem-estar de Ladário-MS. In: SEMINÁRIO INTERNACIONAL DE PÓSGRADUAÇÃO EM DESENVOLVIMENTO RURAL SUSTENTÁVEL, 1; JORNADA QUESTÃO AGRÁRIA E DESENVOLVIMENTO, 4. 2017. Marechal Cândido Rondon, PR. Interdisciplinaridade e desenvolvimento rural sustentável. Anais... Marechal Cândido Rondon, PR: UNIOESTE, 2017. Disponível

em:

http://ainfo.cnptia.embrapa.br/digital/bitstream/item/172812/1/COMERCIALIZACAO-

Edison.pdf. Acesso em: 20 nov. 2019.

FAVERET FILHO, P. et al. Agricultura Orgânica: Quando o passado é futuro. BNDES Setorial, Rio de Janeiro, n. 15, p. 3-34, mar. 2002. Disponível em: http://web.bndes.gov.br/bib/jspui/handle/1408/2479. Acesso em: 15 mar. 2019.

FAVERO, E., \& SARRIERA, J. C. Extensão rural e intervenção: velhas questões e novos desafios para os profissionais. Cadernos de Psicologia Social do Trabalho, v. 12, n. 1, p. 1-16, 2009. https://doi.org/10.11606/issn.1981-0490.v12i1p1-16.

FONSECA, M. F. A. C. A institucionalização dos mercados de orgânicos no mundo e no Brasil: uma interpretação. 2005. 476 f. Tese (doutorado em Sociologia) - Seropédica: UFRuraIRJ, ICHS, CPDA, 2005. Disponível em: https://www.ciorganicos.com.br/wpcontent/uploads/2013/09/Mercado-organicos-MFFonseca.pdf. Acesso em: 15 mar. 2019.

FRISON, E.; ROVER, O. J. Entraves para a certificação orgânica do leite numa central cooperativa de agricultores familiares do oeste catarinense. Rev. Bras. de Agroecologia, v. 9, n. 2, p. 70-83, 2014. Disponível em: http://revistas.abaagroecologia.org.br/index.php/rbagroecologia/article/view/15377. Acesso em: 15 mar. 2019.

GALHARDO, L. R.; SILVA, L. F. S.; LIMA, A. S. F. Produtores orgânicos no Brasil e seus organismos certificadores. Revista Ciência, Tecnologia \& Ambiente, v. 8, n. 1, p. 37-45, 2018. Disponível em: http://www.revistacta.ufscar.br/index.php/revistacta/article/view/129. Acesso em: 02 fev. 2020. http://dx.doi.org/10.4322/2359-6643.08105. 
30 | Transição para a produção orgânica via Organização de Controle Social do Grupo Bem-Estar, Ladário-MS

HAAS, J. M.; RAMBO, A. G.; BOLTER, J. A. G. Os Núcleos de Estudo em Agroecologia e Produção Orgânica (NEA) enquanto mecanismos de desenvolvimento regional: algumas considerações. Colóquio, Revista do Desenvolvimento Regional, Taquara/RS, Edição Especial II SNDR, p. 185205, jan. 2019. Disponível em: https://seer.faccat.br/index.php/coloquio/article/view/1222. Acesso em: 02 fev. 2020. https://doi.org/10.26767/coloquio.v16i2.1222.

IBGE. Instituto Brasileiro de Geografia e Estatística. Censo agropecuário 2017. Rio de Janeiro: IBGE, 2017. Disponível em: https://www.ibge.gov.br/estatisticas/economicas/agricultura-epecuaria/21814-2017-censo-agropecuario.html. Acesso em: 07 mai. 2020.

KUKIEL, E. D. G.; CUYATE, R.; COSTA, E. A. O efeito fronteira em Corumbá e Ladário, MS, Brasil: breve olhar sobre a construção civil e produção de hortaliças. Revista GeoPantanal, v. 7, n.13, p. 113-126, 2012.

LIN, L., ZHOU, D.; MA, C. Green food industry in China: Development, problems and policies. Renewable Agriculture and Food Systems, v. 25, n. 1, p. 69-80, 2010. Acesso em: 10 mai. 2020. DOI: https://doi.org/10.1017/S174217050999024X.

LUIZZI, D., FERREIRA, J. D., SCHNEIDER, M. B. O comércio internacional de produtos orgânicos: atuação do Brasil e de países atuantes no setor. Caderno de Administração, v. 24, n. 2, p. 72 88, 2016. Disponível em: http://periodicos.uem.br/ojs/index.php/CadAdm/article/view/32725. Acesso em: 20 mai. 2020. https://doi.org/10.4025/cadadm.v24i2.32725

MAAS, L. et al. Agricultura orgânica: uma tendência saudável para o produtor. Cadernos de Ciência \& Tecnologia, Brasília, v. 35, n. 1, p. 75-92, jan./abr. 2018. Disponível em: https://ainfo.cnptia.embrapa.br/digital/bitstream/item/184821/1/Agricultura-organica-umatendecnia.pdf. Acesso em: 20 fev. 2020.

MARQUES, P. E. M.; GASPARI, L.; ALMEIDA, B. Organização de Controle Social (OCS) e engajamento agroecológico das famílias do assentamento Milton Santos no estado de São Paulo. Estudos Sociedade e Agricultura, v. 25, n. 3, p. 545-560, 2017. Disponível em: https://revistaesa.com/ojs/index.php/esa/article/view/ESA25-3_04_organizacao. Acesso em: 03 mar. 2020. https://doi.org/10.36920/esa-v25n3-4.

MATOS, A. K. V. Revolução verde, biotecnologia e tecnologias alternativas. Cadernos da FUCAMP, v. 10, n. 12, p. 1-17, 2011 . Disponível em: http://www.fucamp.edu.br/editora/index.php/cadernos/article/view/134. Acesso em: 03 mar. 2020.

MOREIRA, J. G.; BECKER, C. Implantação de um sistema participativo de certificação orgânica pelos assentados da reforma agrária: o caso do OCS Cerro dos Munhoz em Santana do Livramento (RS). ACTA Geográfica, Boa Vista, v.12, n. 28, p. 1-16, jan./abr. de 2018. Disponível em: https://revista.ufr.br/actageo/article/view/4155. Acesso em: 05 mai. 2020. http://dx.doi.org/10.5654/acta.v12i28.4155. 
MOREIRA, R. J. Críticas ambientalistas à revolução verde. Estudos sociedade e agricultura, v. 15, p. 39-52, out. $2000 . \quad$ Disponível em: https://revistaesa.com/ojs/index.php/esa/article/view/176. Acesso em: 07 abr. 2020.

NEVES, M. C. P. Cadeia de produtos orgânicos: aspectos relacionados com a qualidade e o mercado. Documentos. Rio de Janeiro: Embrapa Agrobiologia, 2004. Disponível em: https://www.infoteca.cnptia.embrapa.br/infoteca/bitstream/doc/627841/1/doc185.pdf. Acesso em: 02 fev. 2020.

PADOVAN, D. S. S. Avanços e desafios no processo de certificação da produção orgânica no Estado de Mato Grosso do Sul. 2016. 133 f. Dissertação (Mestrado em Agronegócios) Universidade Federal da Grande Dourados, Dourados, 2016. Disponível em: http://repositorio.ufgd.edu.br/jspui/bitstream/prefix/1360/1/DeniseSoaresdaSilvaPadovan.pdf. Acesso em: 02 jun. 2020.

PERON, V.; COSTA, E. A.; ARRUDA, J. C. C. Definição de preços de produtos agroecológicos: o caso do Grupo Bem-Estar no assentamento 72, em Ladário/MS. Cadernos de Agroecologia, v. 13, n. 2, dez. 2018. Disponível em: http://cadernos.abaagroecologia.org.br/index.php/cadernos/article/view/2255. Acesso em: 05 mai. 2020.

PINHA, G. A.; ALMEIDA, R. A. As feiras agroecológicas da Reforma Agrária em Três Lagoas/MS: produção sustentável e consumo informado. Cadernos de agroecologia, v. 13, n. 2, p. 1-10, 2018. Disponível em: http://cadernos.abaagroecologia.org.br/index.php/cadernos/article/view/2209. Acesso em: 10 jun. 2020.

PINHEIRO, K. H. Produtos orgânicos e certificação: o estudo desse processo em uma associação de produtores do município de Palmeira-PR. 2012. 116 f. Dissertação (Mestrado em Engenharia de Produção) - Universidade Tecnológica Federal do Paraná, Ponta Grossa, 2012. Disponível em: http://repositorio.utfpr.edu.br/jspui/handle/1/582. Acesso em: 05 jun. 2020.

PIZZAIA, L. G. E. et al. A Organização de Controle Social no mercado de orgânicos: um estudo de caso. In: SIMPÓSIO REFORMA AGRÁRIA E QUESTÕES RURAIS, 8. 2018. Anais... Araraquara, 2018. p. 1-16. Disponível em: https://www.uniara.com.br/legado/nupedor/nupedor_2018/4B/7_Luiz_Pizzaia.pdf. Acesso em: 05 jun. 2020.

POZZEBON, L.; RAMBO, A. G.; GAZOLLA, M. As cadeias curtas das feiras coloniais e agroecológicas: autoconsumo e segurança alimentar e nutricional. Desenvolvimento em questão, Editora Unijuí, ano 16, n. 42, p. 405-441, jan./mar. 2018. Disponível em: https://www.redalyc.org/jatsRepo/752/75253741020/html/index.html. Acesso em: 02 jun. 2020. https://doi.org/10.21527/2237-6453.2018.42.405-441.

SAMBUICHI, R. H. R. et al. Introdução. In. (Org.). A política nacional de agroecologia e produção orgânica no Brasil: uma trajetória de luta pelo desenvolvimento rural sustentável. Brasília: IPEA, 2017. p. 11-22. 
32 | Transição para a produção orgânica via Organização de Controle Social do Grupo Bem-Estar, Ladário-MS

SANTOS, L. et al. Políticas públicas para o comercio de produtos orgânicos no Brasil. Rev. de Ciências Agrarias, Lisboa, v.40, n.2, p. 170-180, jun. 2017. Disponível em: http://www.scielo.mec.pt/scielo.php?script=sci_arttext\&pid=S0871-

018X2017000200017\&lng=pt\&nrm=iso. Acesso em: 20 mai. 2020. http://dx.doi.org/10.19084/RCA16131.

SILVA, E. S. C. O caminho da transição agroecológica para a produção orgânica do grupo bem-estar, do assentamento 72, Ladário-MS. 2019. 52 f. Monografia (Graduação em Geografia) - Universidade Federal de Mato Grosso do Sul, Corumbá, 2019. Disponível em: https://ppgefcpan.ufms.br/repositorio-de-dissertacoes-2. Acesso em: 20 fev. 2020.

SOUSA, A. A. et al. Alimentos orgânicos e saúde humana: estudo sobre as controvérsias. Revista Panamericana de Salud Pública, v. 31, p. 513-517, 2012. Disponível em: https://scielosp.org/pdf/rpsp/2012.v31n6/513-517/pt. Acesso em: 27 out. 2019.

SOUZA, R. P.; BATISTA, A. P.; CÉSAR, A. S. As tendências da certificação de orgânicos no Brasil. Estudos Sociedade e Agricultura, v. 27, n. 1, p. 95-117, 2019. Disponível em: https://revistaesa.com/ojs/index.php/esa/article/view/ESA27-1_as_tendencias_da_certificacao. Acesso em: 10 jun. 2020. https://doi.org/10.36920/esa-v27n1-5.

VRIESMAN, A. K. et al. Assistência técnica e extensão rural para a certificação de produtos orgânicos da agricultura familiar. Revista Conexão UEPG, v. 8, n. 1, p. 138-149, 2012. Disponível em:

https://www.researchgate.net/publication/279346534_ASSISTENCIA_TECNICA_E_EXTENSAO_R URAL_PARA_A_CERTIFICACAO_DE_PRODUTOS_ORGANICOS_DA_AGRICULTURA_FAMILIAR. Acesso em: 30 out. 2019.

WEID, J. M. von der. Agroecologia e agricultura familiar para o aumento da segurança alimentar: uma visão geral. In. BOTELHO FILHO, F. B. (Org.). Agricultura familiar e desenvolvimento territorial: contribuições ao debate. Brasília: Universidade de Brasília, Núcleo de Estudos Avançados, v.5, n.17, 2005. p. 59-79.

\section{1 - Edgar Aparecido da Costa:}

Geógrafo, doutor em Geografia, docente da Universidade Federal de Mato Grosso do Sul, Campus do Pantanal,

http://orcid.org/0000-0002-0043-2642•edgarac10@gmail.com

Contribuição: Primeira redação, correção.

\section{2 - Bárbara Marcela de Castro Martins:}

Graduada em Geografia pela Universidade Federal do Mato Grosso do Sul (UFMS), Campus do Pantanal, http://orcid.org/0000-0002-7307-3134• barbara.martins.castro@hotmail.com Contribuição: Primeira redação, confecção dos mapas, entrevistas. 


\section{3 - Elisângela de Souza Cunha:}

Licenciada em Geografia pela Universidade Federal de Mato Grosso do Sul (UFMS), Campus do Pantanal

http://orcid.org/0000-0002-9909-569X•elisangelasouzacunha@gmail.com Contribuição: Escrita - Primeira Redação, entrevistas.

\section{Como citar este artigo}

COSTA, E. A. da; MARTINS, B. M. de C; CUNHA, E. de S. Transição para a produção orgânica via Organização de Controle Social do Grupo Bem-Estar, Ladário-MS. Geografia Ensino \& Pesquisa, Santa Maria, v.25, e37, p. 1-33, 2021. DOI 10.5902/2236499464359. Disponível em: https://doi.org/10.5902/2236499464359. Acesso em: dia mês abreviado. ano. 